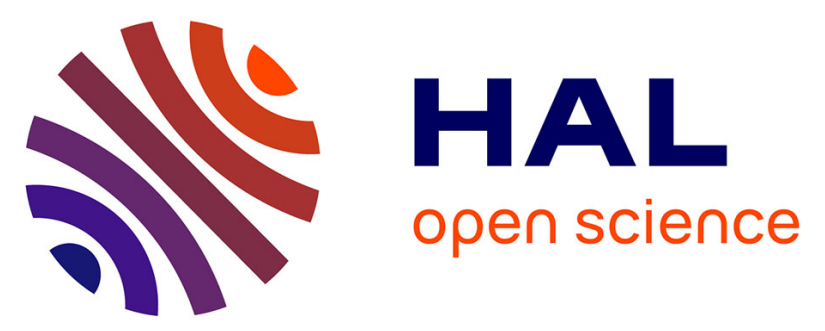

\title{
Fuzzy C-Means Clustering of Signal Functional Principal Components for Post-Processing Dynamic Scenarios of a Nuclear Power Plant Digital Instrumentation and Control System
}

\author{
Francesco Di Maio, Piercesare Secchi, Simone Vantini, Enrico Zio
}

\section{To cite this version:}

Francesco Di Maio, Piercesare Secchi, Simone Vantini, Enrico Zio. Fuzzy C-Means Clustering of Signal Functional Principal Components for Post-Processing Dynamic Scenarios of a Nuclear Power Plant Digital Instrumentation and Control System. IEEE Transactions on Reliability, 2011, 60 (2), pp.415-425. 10.1109/TR.2011.2134230 . hal-00609634

\section{HAL Id: hal-00609634}

https://hal-centralesupelec.archives-ouvertes.fr/hal-00609634

Submitted on 27 Jul 2012

HAL is a multi-disciplinary open access archive for the deposit and dissemination of scientific research documents, whether they are published or not. The documents may come from teaching and research institutions in France or abroad, or from public or private research centers.
L'archive ouverte pluridisciplinaire HAL, est destinée au dépôt et à la diffusion de documents scientifiques de niveau recherche, publiés ou non, émanant des établissements d'enseignement et de recherche français ou étrangers, des laboratoires publics ou privés. 


\title{
FUZZY C-MEANS CLUSTERING OF SIGNAL FUNCTIONAL PRINCIPAL COMPONENTS FOR POST-PROCESSING DYNAMIC SCENARIOS OF A NUCLEAR POWER PLANT DIGITAL INSTRUMENTATION AND CONTROL SYSTEM
}

\author{
Francesco Di Maio ${ }^{\mathrm{a}}$, Piercesare Secchi $^{\mathrm{b}}$, Simone Vantini $^{\mathrm{b}}$, Enrico Zio $^{\mathrm{a}, \mathrm{c}}$ \\ ${ }^{a}$ Energy Department, Politecnico di Milano, Via Ponzio 34/3, 20133 Milano, Italy, enrico.zio@polimi.it \\ ${ }^{b}$ MOX, Department of Mathematics, Politecnico di Milano, via Bonardi 9, 20133 Milano, Italy \\ ${ }^{c}$ Ecole Centrale Paris and Supelec, Grande Voie des Vignes, 92295 Chatenay-Malabry Cedex, France
}

\begin{abstract}
This paper addresses the issue of the classification of accident scenarios generated in a dynamic safety and reliability analyses of a Nuclear Power Plant (NPP) equipped with a Digital Instrumentation and Control system $(I \& C)$.

More specifically, the classification of the final state reached by the system at the end of an accident scenario is performed by Fuzzy C-Means clustering the Functional Principal Components (FPCs) of selected relevant process variables. The approach allows capturing the characteristics of the process evolution determined by the occurrence, timing, and magnitudes of the fault events.

An illustrative case study is considered, regarding the fault scenarios of the digital $I \& C$ system of the Lead Bismuth Eutectic eXperimental Accelerator Driven System (LBE$X A D S)$. The results obtained are compared with those of the Kth Nearest Neighbor (KNN) and Classification and Regression Tree (CART) classifiers.
\end{abstract}

Keywords: dynamic reliability, fault scenarios classification, functional principal components analysis, fuzzy clustering, Fuzzy C-Means, digital instrumentation and control faults, nuclear power plants. 


\section{Introduction}

Nuclear Power Plants (NPPs) are replacing and upgrading their aging and obsolete Instrumentation and Control ( $\mathrm{I} \& \mathrm{C}$ ) components, with a transition from analog to digital technology. Furthermore, new NPP designs involve an increased use of computer-based systems, expected to improve the plant's safety, reliability and failure detection capability.

To assess the impact of digital I\&C on NPPs safety, quantifiable reliable models are needed, along with data for digital systems that are compatible with the Probabilistic Risk Assessment Methodology (PRA). Due to the many unique attributes of these systems (e.g., software, fault tolerant features, different human-system interfaces, dynamic interaction between the plant system and processes), several challenges exist in modeling and data collection.

The feature addressed in this paper is limited to the modeling of the dynamic interactions between the plant systems and processes, which in many instances regards both analog and digital I\&C systems. Indeed, it has been shown that the order and timing of the fault events occurring along an accident sequence and the magnitude of the process variables at the time of event occurrence can be critical in determining the evolution of the accident and thus the risk associated with the system operation [Siu, 1994; Aldemir et al., 2008]. In the case of digital I\&C systems the modeling is rendered more difficult by the complex interactions of the software with the hardware and human components that are not easily captured by the existing PRA modeling tools, e.g., the Event-Tree (ET)/Fault-Tree (FT) approach which do not take explicitly into account the sequencing of the events nor their timing in the system stochastic evolution [Rutt et al., 2006, Zio et al., 2009].

Methodological approaches have been studied and practical tools are being developed, in an effort to complement the current static PRA methods and tools. These so-called dynamic reliability [Devooght, 1997; Labeau et al., 2000; Dufour et al, 2002] or probabilistic dynamics [Devooght et al., 1992a; Devooght et al., 1992b] methods aim at giving explicit account to the interactions among the physical parameters of the process (temperature, pressure, speed, etc.), the human operators actions and the failures of the hardware and software components.

Some extensions of classical methods have been proposed but in most instances these remain unable to take into account the system state dynamic changes and reconfigurations along the accident scenarios and their application is limited to problems with a small number of scenarios [Medjoudj et al., 2004]. Some methods allow a visual presentation of the sequence of events ordered in time, e.g. the Events Sequence Diagrams (ESD) [Swaminathan et al., 1999], Petri Nets [Peterson, 1977] and Dynamic Flowgraph Methodology (DFM) [Guarro et al., 1996; Garret et al., 2002]. Most of these methods can be regarded as semi-dynamic, because they represent system dynamics qualitatively (e.g., Petri Nets) or in a coarse partitioning of the system state space (i.e., in terms of large, small, medium changes in the controlled process variables such as in DFM).

Discrete methods have also been developed to generate dynamic failure scenarios, e.g. the Discrete Dynamic Event Trees (DDET) [Marchand et al., 1998], the DYnamic Logical Analytical Methodology (DYLAM) [Amendola et al., 1984; Cojazzi, 1996] and the Dynamic Event Tree Analysis Method (DETAM) [Acosta et al., 1993]. The advantage of the dynamic event-tree generation techniques (such as DDET, DYLAM and DETAM) is that they are compatible with the existing PRA structure and are able to generate possible scenarios of the system evolution exhaustively.

A major challenge of the dynamic reliability techniques is their computational complexity, both in model construction and implementation. Indeed, the number of dynamic scenario branches increases according to the power law with the number of occurring events and thus is much larger than in the classical FT/ET approach; the a posteriori information retrieval then becomes quite burdensome and difficult [Labeau et al., 2000]. 
The work in this paper reconsiders the problem of processing dynamic reliability scenarios as formulated in [Zio et al., 2009], i.e., in terms of the classification of dynamic patterns on the basis of the similarity of both their stochastic features (i.e., times and magnitudes of failure event occurrences) and deterministic features (i.e., process variable values, such as temperatures and pressures). In general terms, the nature and complexity of the scenarios prevent the possibility of identifying crisp clusters of similarity in the features space (Figure 1); uncertainties and overlaps exist in the association of the accident sequences to the three end state classes. Such situation can be effectively tackled within a fuzzy clustering paradigm for classification [Klir et al., 1995].

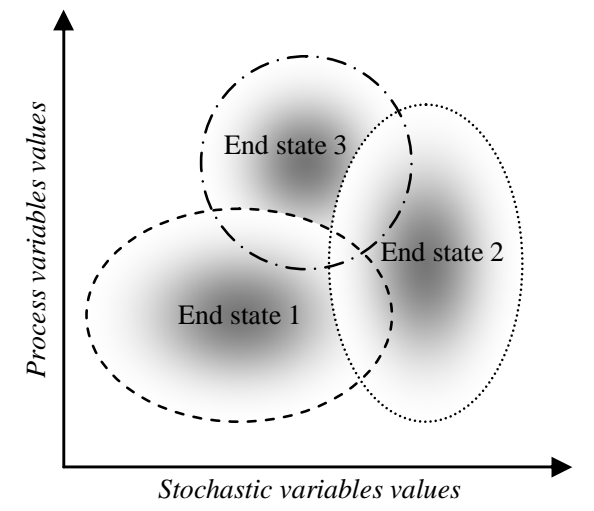

Figure 1 Schematics of the clustering of the accident sequences for classification of their end states, based on the combination of process and stochastic variables information

In Figures 2 and 3, the logic framework and operative steps for the classification of the scenarios are sketched. Figure 2 (left) shows that the larger the number of failure modes, the larger the number of branches in a traditional ET, which can become infinite if considering the continuous stochastic times and magnitudes of the failure modes within a continuous ET framework [Amendola et al., 1984; Smidts, 1994]; the dynamic scenario post-processing here proposed is aimed at classifying these branches into a small number of representative clusters of scenarios with common evolution features and leading to one of the pre-defined end states (right). The classification algorithm is built on a limited number of accident scenarios and can then be used to evaluate new accident scenarios for identifying their end states; this leads to savings in the computational time which makes feasible the dynamic analysis, irrespective of the number of system configurations to be considered.

In more details, the first step of the approach is the selection of the features of the scenarios relevant for the classification; the second step is the evolutionary training of the clustering algorithm on patterns of known classes. The latter one essentially involves the search for geometric clusters in the feature space based on a metric iteratively optimized so that the clusters finally obtained are close to the actual classes of scenarios of same end state [Jain et al., 1988]. 


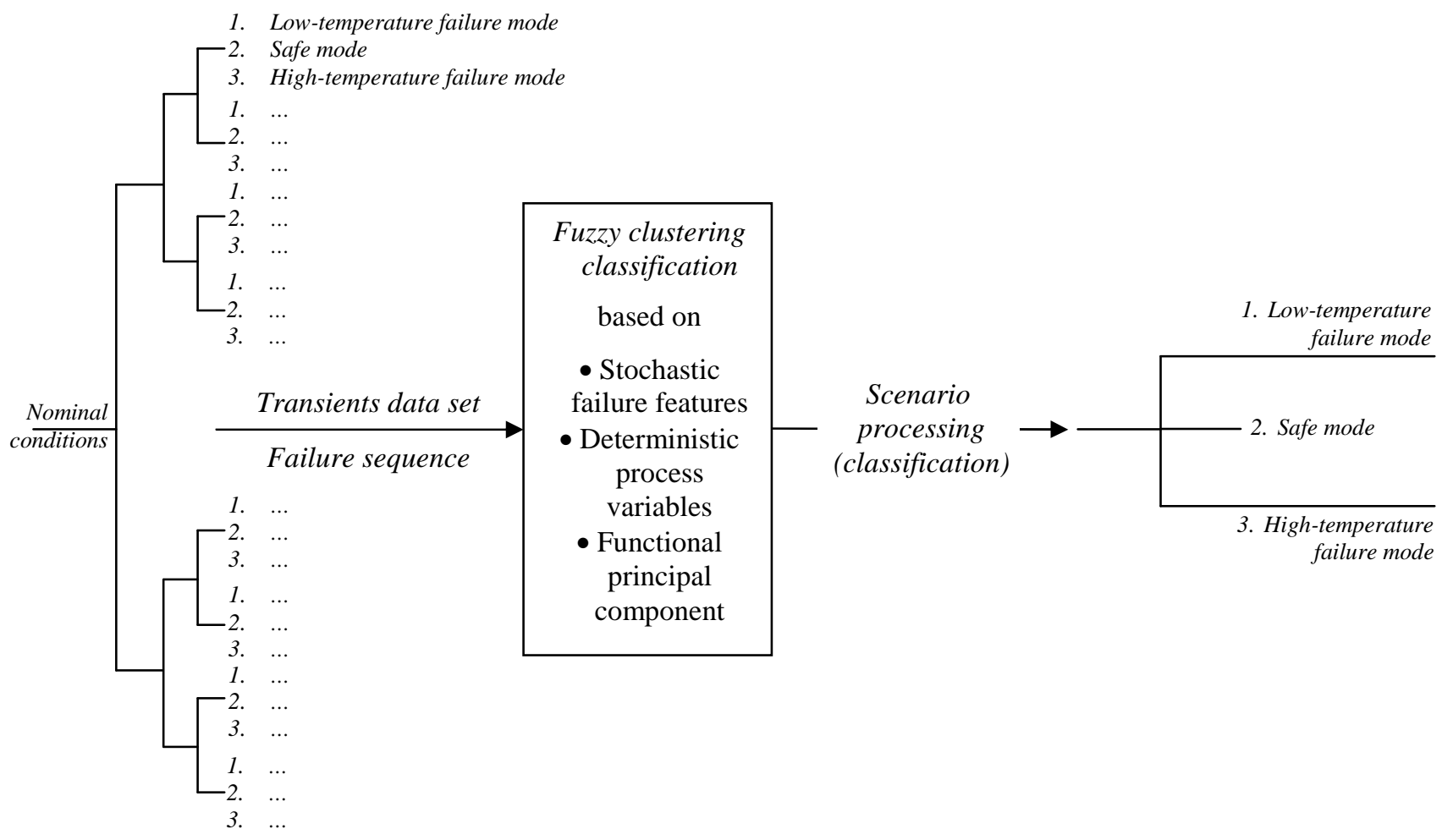

Figure 2 Dynamic scenario classification into a low number of branches corresponding to the clusters of scenarios sharing common stochastic and deterministic evolution features which lead to one of the pre-defined end states

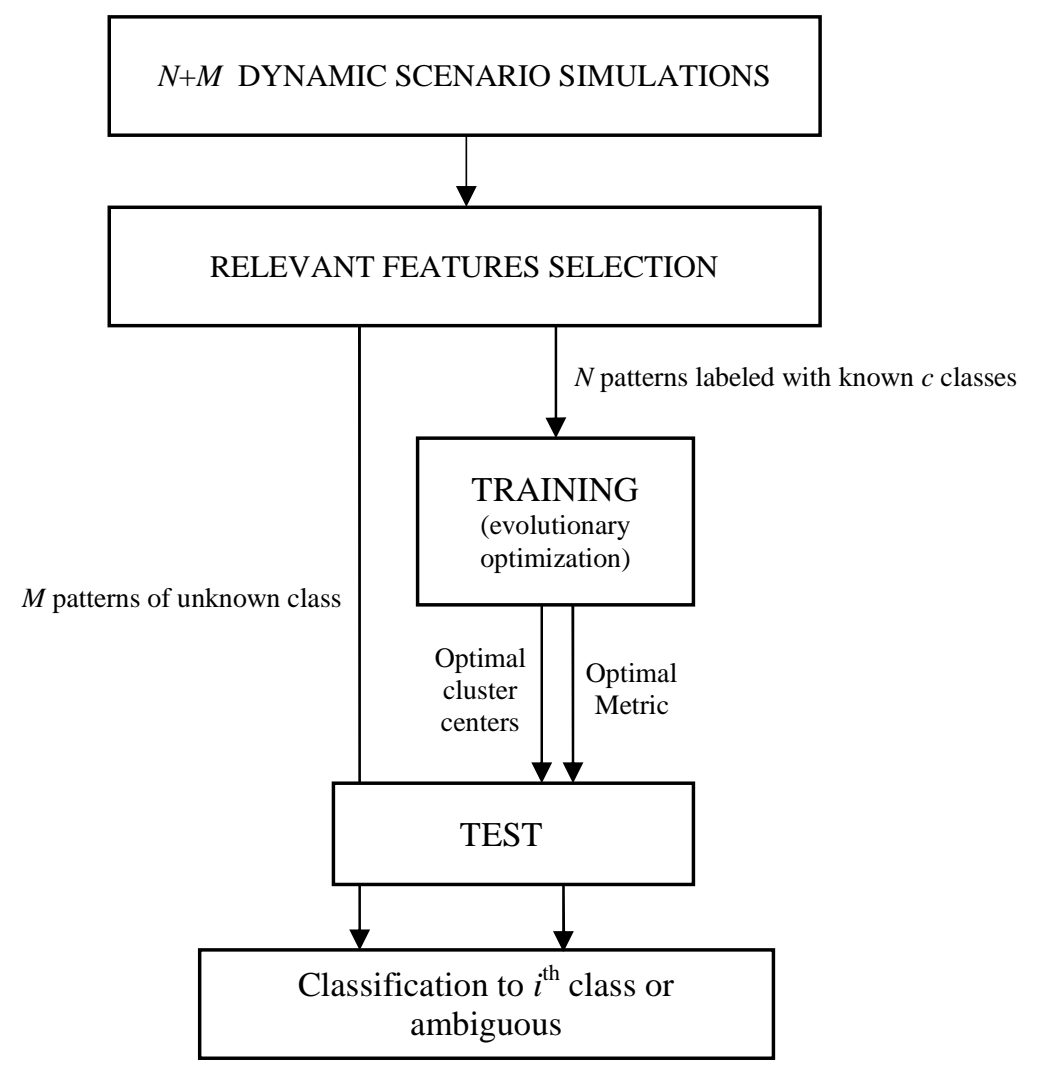

Figure 3 The operative steps of the scenario classification approach 
As in [Zio et al., 2009], the supervised Fuzzy C-Means (FCM) clustering algorithm developed in [Bezdek, 1981; Zio et al., 2005; Mercurio et al., 2008] is utilized as classifier of the accident scenarios. The original objective of the present work is the investigation of the feasibility of applying Functional Principal Component analysis for representing in a finite dimensional space with uncorrelated components, the characteristics of the accident scenarios that are typically nonfinite nor immediately describable by means of uncorrelated components [Ramsay et al., 2005].

As additional original contribution with respect to the previous work in [Zio et al., 2009], the present study offers a comparison with a Kth Nearest Neighbor (KNN) [Hastie et al., 2001] and a Classification and Regression Tree (CART) [Breiman et al., 1984] algorithms for classification of the end state classes of the dynamic accident scenarios simulated.

The case study considered for illustration is also the same as in the previous cited work, i.e., the dynamic scenarios are taken from the analysis of the Lead Bismuth Eutectic eXperimental Accelerator Driven System (LBE-XADS) equipped with digital I\&C [Cammi et al., 2006].

This work focuses on scenario classification. For this reason, the analysis does not cover the study of the software and its possible failure modes, nor the benefit of fault tolerant features, nor the interactions of the software with the hardware and human components. The simplified dynamic scenario modeling is then intended to serve the purpose of showing the feasibility of effectively post-processing accident scenarios resorting to a FCM clustering algorithm based on the information provided by the FPCs. The classification results could then be used for the identification of the system prime implicants, i.e., the dynamic equivalent of the minimal cut sets of the system under analysis [Aldemir et al., 2008]. Moreover, it is worth pointing out that the actual implementation of the approach as a qualified tool in support of a complete quantitative dynamic reliability analysis and its inclusion in PRA would need to be supported by full dynamic accident calculations, inclusive of comprehensive models of hardware, software and human failure modes and their interactions.

The paper is organized as follows. In Section 2, the presentation made in [Zio et al., 2009] of the mechanistic model used to generate the scenarios for the dynamic reliability analysis of the LBEXADS is repeated, for completeness of the paper. In Section 3, some limitations of traditional static PRA modeling tools (ET/FT) are shown; these limits can be overcome by means of a classification method of dynamic scenarios based on FCM clustering of FPCs. In Section 4, the results of the application of the approach to the scenarios of the LBE-XADS are presented and supported with a comparison to the KNN and CART classifiers. Conclusions and remarks are given in Section 5.

\section{Analysis of the LBE-XADS}

\subsection{The model}

The Lead-Bismuth Eutectic eXperimental Accelerator Driven System (LBE-XADS) is a subcritical, fast reactor in which the fission process for providing thermal power $P(t)$ is sustained by an external neutron source through spallation reaction by a proton beam $Q(t)$ accelerated by a synchrotron on a lead-bismuth eutectic target [Bowman et al., 1992; Van Tuyle et al., 1993; Venneri et al., 1993; Carminati et al., 1993; Rubbia et al., 1995]. In the current design [Ansaldo, 2001], the core contains Uranium and Plutonium dioxide fuel rods; future developments are aimed at housing also long-lived transuranic elements.

A simplified scheme of the plant is sketched in Figure 4. The primary cooling system is of pooltype with Lead-Bismuth Eutectic (LBE) liquid metal coolant leaving the top of the core, at full power nominal conditions, at temperature $\tau_{L B}^{C, P}$ equal to $400{ }^{\circ} \mathrm{C}$ pushed by natural circulation enhanced by argon gas injection into the heat exchangers of the secondary cooling circuit and then 
re-entering the core from the bottom through the down-comer at temperature $\tau_{L B}^{P, C}$ equal to $300{ }^{\circ} \mathrm{C}$. The average in-core temperature of the LBE $T_{L B}^{a v, C}$ is taken as the mean of $\tau_{L B}^{C, P}$ and $\tau_{L B}^{P, C}$.

The secondary cooling system is a flow of an organic diathermic oil at 290-320 ${ }^{\circ} \mathrm{C}$, at full power conditions. Cooling of the diathermic oil is obtained through an air flow $\Gamma_{a}(t)$ provided by three air coolers connected in series.

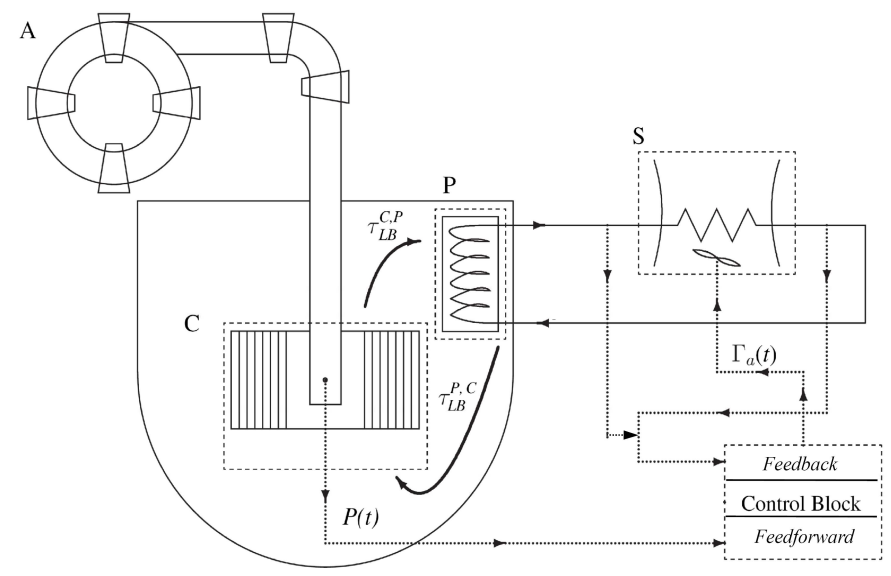

Figure 4 LBE-XADS simplified schematics. $A$ = Accelerator; $C=$ core; $P=$ primary heat exchanger; $S=$ secondary heat exchanger

A dedicated, dynamic simulation model has been implemented in SIMULINK for providing a simplified, lumped and zero-dimensional description of the coupled neutronic and thermo-hydraulic evolution of the system [Cammi et al., 2006]. The model allows the simulation of the system controlled dynamics as well as of the free dynamics when the control module is deactivated and the air cooler flow is kept constant. Both feedforward and feedback digital control schemes have been adopted for the operation of the system. The feedback controller is a PID (Proportional, Integral and Derivative)-based configuration with low values of both the proportional and the integral gains: it contributes for $70 \%$ of the load to fulfill the control strategy. On the other hand, the remaining $30 \%$ of the load is provided by the feedforward action which consists of a monotonically increasing function relating the required air mass flow rate to the reactor power. The logic of operation of the discrete-state control block can be represented as in Figure 5.

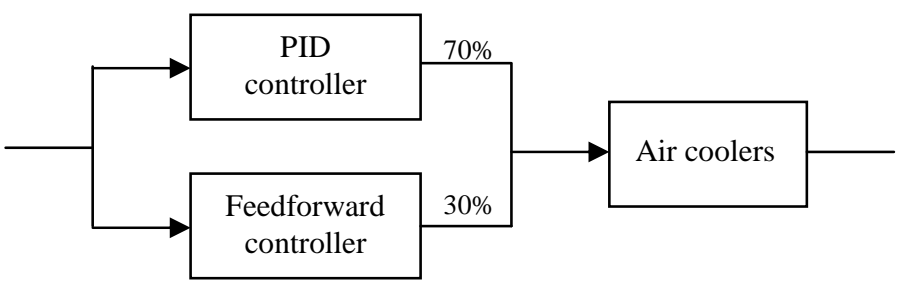

Figure 5 Block diagram representing the logic structure of the LBE-XADS control

The control is set to keep a steady state value of approximately $300{ }^{\circ} \mathrm{C}$ of the average temperature of the diathermic oil $T_{o}^{a v, S}$ : this value represents the optimal working point of the diathermic oil at the steady state, full nominal power of $80 \mathrm{MW}_{\text {th }}$. On the contrary, an oil temperature beyond the upper threshold $T_{o}^{t h, u}=340{ }^{\circ} \mathrm{C}$ would lead to degradation of its physical and chemical properties, whereas a temperature below the lower threshold $T_{o}^{\text {th }, l}=280{ }^{\circ} \mathrm{C}$ could result in thermal shocks for the primary fluid and, eventually, for the structural components [Cammi et al., 2006]. 
The block diagram representing the SIMULINK model of the LBE-XADS is shown in Figure 6: the controlled variable is the average temperature of diathermic oil $\left(T_{o}^{a v, S}\right)$, whereas the control variable is the mass flow rate of air $\left(\Gamma_{a}\right)$ in the air coolers battery. In Figure 7 , the profile of the average temperature of diathermic oil $\left(T_{o}^{a v, S}\right)$ at full power nominal conditions is shown: even if the system is stable at nominal conditions $\left(303.85^{\circ} \mathrm{C}\right)$, the discrete-state regulation of the air coolers causes visible ripples of the diathermic oil temperature.

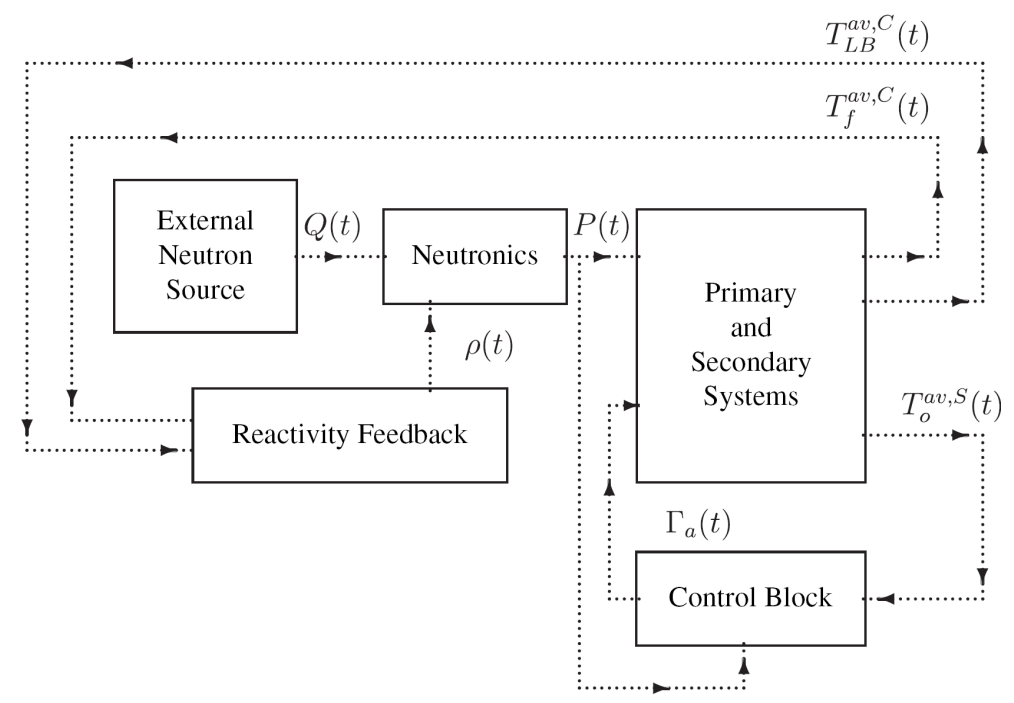

Figure 6 Block diagram representing the SIMULINK model of the LBE-XADS [Cammi et al., 2006]

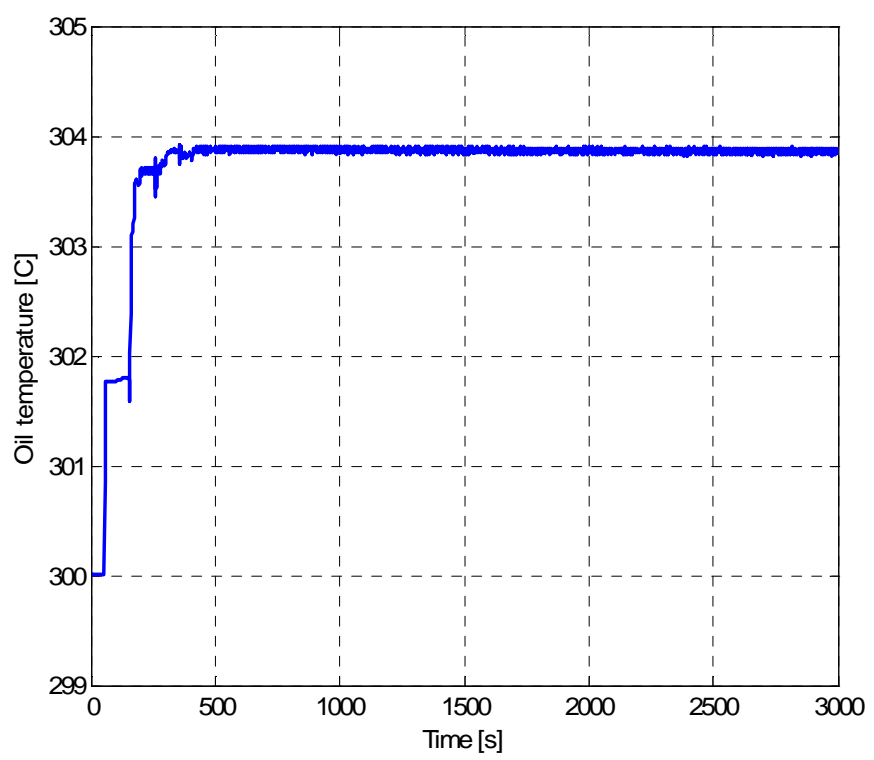

Figure 7 Diathermic oil temperature profile for the LBE-XADS in the stable, nominal conditions

\subsection{The Monte Carlo-driven fault injection engine}

Multiple component failures can occur during the system life. To simulate this, the model has been embedded within a Monte Carlo (MC) sampling procedure for injecting faults at random times and of random magnitudes. This allows generating transients representative of the system dynamic accident scenarios. 
The set of faults considered are (Figure 8):

- The PID controller fails stuck at time $t_{1}$ in $[0,3000]$ [s], with a flow rate output of magnitude $m_{1}$ in $[0,797][\mathrm{kg} / \mathrm{s}]$.

- The air coolers fail stuck at time $t_{2}$ in $[0,3000]$ [s] in a random position that provides a corresponding air flow mass $m_{2}$ in $[0,1000][\mathrm{kg} / \mathrm{s}]$.

- The feedforward controller fails stuck at time $t_{3}$ in [0,3000] [s] with a corresponding flow rate value $m_{3}$ in $[0,797][\mathrm{kg} / \mathrm{s}]$.

- The communication between air coolers actuators and PID controller fails at time $t_{4}$ in $[0,3000][\mathrm{s}]$ so that the PID is provided with the same input value of the previous time step.

The combination of the selected faults gives rise to 64 possible system configurations depending on the number of failed components and the order of occurrence of the failures (Table 1). It is important to underline that the procedure implemented in this work for sampling the fault events is not intended to reproduce the actual stochastic failure behavior of the system components; rather, the choices and hypotheses for modeling the faults (i.e., the mission time, the number and typology of faults, the distributions of failure times and magnitudes) have been arbitrarily made with the aim of favoring multiple failures in the sequences and capturing the dynamic influence of their order, timing, and magnitude.

In particular, times and magnitudes of faults are obtained by a stratified sampling with respect to the 64 possible ordered accident sequences of Table 1, assumed equally probable. Within each stratum (i.e., given one of the 64 possible ordered sequences), the corresponding failure times are generated by means of a "stick-breaking" strategy [Halmos, 1944]: the first failure time is sampled from the uniform distribution $[0,3000][\mathrm{s}]$ and the successive failure times from the conditional distributions, uniform from the last sampled time to 3000 [s]. Failure magnitudes are instead independently sampled from uniform distributions in [0,797], [0,1000] and [0,797] [kg/s] for $m_{1}, m_{2}$, and $m_{3}$, respectively. This sampling strategy models a wearing system, since the average failure rate is increasing along time. Moreover, even rare multiple fault events are included in the set of accident scenarios. Thus, it can be easily stated that the experimental set-up is a very conservative assumption and in this sense it further tests the robustness of the classification procedure. On one hand, in real applications these hypotheses can be relaxed, due to the high reliability of the equipment usually adopted in real NPPs; on the other hand, the complete analysis of a realistic system may involve dozens of components and failure modes, whose permutation of occurrence may lead to a combinatorial explosion of the system failure sequences; this, linked with the need of simulating a representative number of scenarios for each sequence, can make the analysis impracticable. To overcome this problem in practice, i) the system failure sequences to be considered will need to be identified by experienced-developed ETs which eliminate some permutations, but in a wise and controlled manner avoiding to ignore some relevant dynamic behaviors or collapsing together accident scenarios which are actually different and lead to different end states [Aldemir et al., 2008]; ii) the simulation of the required number of dynamic accident scenarios for the considered system failure sequences might need to be performed by fast-running empirical models providing sufficiently accurate response surfaces of the system dynamic behavior. The evolution of the accident scenarios may lead to three different end states, within the mission time of 3000 [s]:

1. Low-temperature failure mode $\left(T_{o}^{a v, S}<T_{o}^{t h, l}\right)$

2. Safe mode $\left(T_{o}^{t h, l}<T_{o}^{a v, S}<T_{o}^{t h, u}\right)$

3. High-temperature failure mode $\left(T_{o}^{a v, S}>T_{o}^{t h, u}\right)$ 


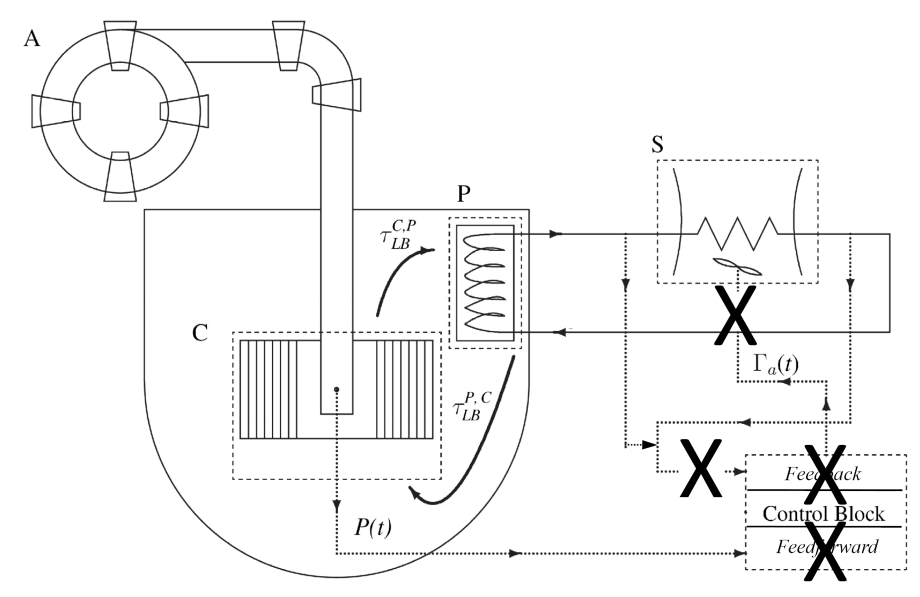

Figure 8 Sketch of the faults that can be injected into the system: the PID controller fails stuck at a random output value, the air coolers fails stuck at a random position, the feedforward control fails stuck at a random output value, the communication between air coolers actuators and the PID controller is interrupted

\begin{tabular}{|c|c|c|c|c|}
\hline $\begin{array}{l}\text { Failure } \\
\text { sequence }\end{array}$ & $\begin{array}{c}\text { Random PID } \\
\text { controller output }\end{array}$ & $\begin{array}{l}\text { Random Air } \\
\text { coolers failure }\end{array}$ & $\begin{array}{l}\text { Random Feedforward } \\
\text { controller output }\end{array}$ & $\begin{array}{c}\text { Actuators-PID } \\
\text { communication interruption }\end{array}$ \\
\hline 1 & $1^{\mathrm{st}}$ & - & - & - \\
\hline 2 & - & $1^{\text {st }}$ & - & - \\
\hline 3 & - & - & $1^{\text {st }}$ & - \\
\hline 4 & & - & - & $1^{\mathrm{st}}$ \\
\hline 5 & $1^{\mathrm{st}}$ & $2^{\text {nd }}$ & - & - \\
\hline 6 & $2^{\text {nd }}$ & $1^{\mathrm{st}}$ & - & - \\
\hline 7 & $1^{\text {st }}$ & - & $2^{\text {nd }}$ & - \\
\hline 8 & $2^{\text {nd }}$ & - & $1^{\mathrm{st}}$ & - \\
\hline 9 & $1^{\text {st }}$ & - & - & $2^{\text {nd }}$ \\
\hline 10 & $2^{\text {nd }}$ & - & - & $1^{\text {st }}$ \\
\hline 11 & - & $1^{\text {st }}$ & $2^{\text {nd }}$ & - \\
\hline 12 & - & $2^{\text {nd }}$ & $1^{\mathrm{st}}$ & - \\
\hline 13 & - & $1^{\mathrm{st}}$ & - & $2^{\text {nd }}$ \\
\hline 14 & - & $2^{\text {nd }}$ & - & $1^{\text {st }}$ \\
\hline 15 & - & - & $1^{\mathrm{st}}$ & $2^{\text {nd }}$ \\
\hline 16 & - & - & $2^{\text {nd }}$ & $1^{\mathrm{st}}$ \\
\hline 17 & $1^{\mathrm{st}}$ & $2^{\text {nd }}$ & $3^{\text {rd }}$ & - \\
\hline 18 & $1^{\mathrm{st}}$ & $3^{\text {rd }}$ & $2^{\text {nd }}$ & - \\
\hline 19 & $2^{\text {nd }}$ & $1^{\mathrm{st}}$ & $3^{\mathrm{rd}}$ & - \\
\hline 20 & $2^{\text {nd }}$ & $3^{\mathrm{rd}}$ & $1^{\mathrm{st}}$ & - \\
\hline 21 & $3^{\text {rd }}$ & $2^{\text {nd }}$ & $1^{\mathrm{st}}$ & - \\
\hline 22 & $3^{\text {rd }}$ & $1^{\text {st }}$ & $2^{\text {nd }}$ & - \\
\hline 23 & $1^{\mathrm{st}}$ & - & $2^{\text {nd }}$ & $3^{\text {rd }}$ \\
\hline 24 & $1^{\mathrm{st}}$ & - & $3^{\mathrm{rd}}$ & $2^{\text {nd }}$ \\
\hline 25 & $2^{\text {nd }}$ & - & $1^{\mathrm{st}}$ & $3^{\text {rd }}$ \\
\hline 26 & $2^{\text {nd }}$ & - & $3^{\text {rd }}$ & $1^{\text {st }}$ \\
\hline 27 & $3^{\text {rd }}$ & - & $2^{\text {nd }}$ & $1^{\text {st }}$ \\
\hline 28 & $3^{\text {rd }}$ & - & $1^{\mathrm{st}}$ & $2^{\text {nd }}$ \\
\hline 29 & - & $1^{\text {st }}$ & $2^{\text {nd }}$ & $3^{\text {rd }}$ \\
\hline 30 & - & $1^{\mathrm{st}}$ & $3^{\mathrm{rd}}$ & $2^{\text {nd }}$ \\
\hline 31 & - & $2^{\text {nd }}$ & $1^{\mathrm{st}}$ & $3^{\text {rd }}$ \\
\hline 32 & - & $2^{\text {nd }}$ & $3^{\text {rd }}$ & $1^{\mathrm{st}}$ \\
\hline 33 & - & $3^{\text {rd }}$ & $2^{\text {nd }}$ & $1^{\mathrm{st}}$ \\
\hline 34 & - & $3^{\mathrm{rd}}$ & $1^{\mathrm{st}}$ & $2^{\text {nd }}$ \\
\hline 35 & $1^{\mathrm{st}}$ & $2^{\text {nd }}$ & - & $3^{\text {rd }}$ \\
\hline 36 & $1^{\mathrm{st}}$ & $3^{\mathrm{rd}}$ & - & $2^{\text {nd }}$ \\
\hline 37 & $2^{\text {nd }}$ & $1^{\mathrm{st}}$ & - & $3^{\text {rd }}$ \\
\hline 38 & $2^{\text {nd }}$ & $3^{\text {rd }}$ & - & $1^{\mathrm{st}}$ \\
\hline 39 & $3^{\text {rd }}$ & $2^{\text {nd }}$ & - & $1^{\mathrm{st}}$ \\
\hline 40 & $3^{\text {rd }}$ & $1^{\mathrm{st}}$ & - & $2^{\text {nd }}$ \\
\hline 41 & $1^{\mathrm{st}}$ & $2^{\text {nd }}$ & $3^{\text {rd }}$ & $4^{\text {th }}$ \\
\hline 42 & $1^{\mathrm{st}}$ & $3^{\text {rd }}$ & $4^{\text {th }}$ & $2^{\text {nd }}$ \\
\hline 43 & $1^{\mathrm{st}}$ & $4^{\text {th }}$ & $2^{\text {nd }}$ & $3^{\text {rd }}$ \\
\hline 44 & $1^{\text {st }}$ & $2^{\text {nd }}$ & $4^{\text {th }}$ & $3^{\text {rd }}$ \\
\hline
\end{tabular}




\begin{tabular}{|c|c|c|c|c|}
\hline 45 & $1^{\text {st }}$ & $3^{\text {rd }}$ & $2^{\text {nd }}$ & $4^{\text {th }}$ \\
\hline 46 & $1^{\mathrm{st}}$ & $4^{\text {th }}$ & $3^{\text {rd }}$ & $2^{\text {nd }}$ \\
\hline 47 & $2^{\text {nd }}$ & $1^{\mathrm{st}}$ & $3^{\mathrm{rd}}$ & $4^{\text {th }}$ \\
\hline 48 & $3^{\text {rd }}$ & $1^{\text {st }}$ & $4^{\text {th }}$ & $2^{\text {nd }}$ \\
\hline 49 & $4^{\text {th }}$ & $1^{\text {st }}$ & $2^{\text {nd }}$ & $3^{\text {rd }}$ \\
\hline 50 & $2^{\text {nd }}$ & $1^{\text {st }}$ & $4^{\text {th }}$ & $3^{\text {rd }}$ \\
\hline 51 & $3^{\text {rd }}$ & $1^{\mathrm{st}}$ & $2^{\text {nd }}$ & $4^{\text {th }}$ \\
\hline 52 & $4^{\text {th }}$ & $1^{\text {st }}$ & $3^{\text {rd }}$ & $2^{\text {nd }}$ \\
\hline 53 & $2^{\text {nd }}$ & $3^{\text {rd }}$ & $1^{\text {st }}$ & $4^{\text {th }}$ \\
\hline 54 & $3^{\text {rd }}$ & $4^{\text {th }}$ & $1^{\mathrm{st}}$ & $2^{\text {nd }}$ \\
\hline 55 & $4^{\text {th }}$ & $2^{\text {nd }}$ & $1^{\mathrm{st}}$ & $3^{\text {rd }}$ \\
\hline 56 & $2^{\text {nd }}$ & $4^{\text {th }}$ & $1^{\text {st }}$ & $3^{\text {rd }}$ \\
\hline 57 & $3^{\text {rd }}$ & $2^{\text {nd }}$ & $1^{\text {st }}$ & $4^{\text {th }}$ \\
\hline 58 & $4^{\text {th }}$ & $3^{\text {rd }}$ & $1^{\mathrm{st}}$ & $2^{\text {nd }}$ \\
\hline 59 & $2^{\text {nd }}$ & $3^{\text {rd }}$ & $4^{\text {th }}$ & $1^{\mathrm{st}}$ \\
\hline 60 & $3^{\text {rd }}$ & $4^{\text {th }}$ & $2^{\text {nd }}$ & $1^{\mathrm{st}}$ \\
\hline 61 & $4^{\text {th }}$ & $2^{\text {nd }}$ & $3^{\text {rd }}$ & $1^{\mathrm{st}}$ \\
\hline 62 & $2^{\text {nd }}$ & $4^{\text {th }}$ & $3^{\text {rd }}$ & $1^{\mathrm{st}}$ \\
\hline 63 & $3^{\text {rd }}$ & $2^{\text {nd }}$ & $4^{\text {th }}$ & $1^{\mathrm{st}}$ \\
\hline 64 & $4^{\text {th }}$ & $3^{\text {rd }}$ & $2^{\text {nd }}$ & $1^{\mathrm{st}}$ \\
\hline
\end{tabular}

Table 1 Failure sequences: - = safe component, $1^{\text {st }}=$ first event of the sequence, $2^{\text {nd }}=$ second event of the sequence, $3^{\text {rd }}=$ third event of the sequence, $4^{\text {th }}=$ fourth event of the sequence

\subsection{Limitation of traditional approaches}

In order to show $i$ ) the limitation of traditional PRA tools in analyzing dynamic accident scenarios and $i$ ) the feasibility of the approach here proposed for classifying dynamic accident scenarios, the system has been classically analyzed to identify its minimal cut sets with respect to the low- and high-temperature failure modes (the interested reader may refer to [Zio et al., 2009]). To investigate this, the MC-driven fault injection engine introduced in Section 2.2 is used to sample for the 64 system configurations of Table 1, the time and magnitude of the components failures from their probability distributions. With the aim of generating a sufficiently wide variety of system dynamic behaviors, to guarantee the necessary coverage of system failure variability coverage, the number of simulated accident scenarios has been taken equal to 120 for each one of the 64 failure sequences; for each sequence, the random times and magnitudes of the components faults have been sampled from the respective assumed distributions and the SIMULINK model of the LBE-XADS in the sampled system configuration has been run.

Figure 9, reports the frequency of the three system end states (high-temperature, safe, lowtemperature) for the 64 system configurations of Table 1. It is clear that the order, timing and magnitude of the events occurring along an accident scenario determine the evolution of the accident towards safe or fault end states [Aldemir et al., 2008; Zio et al., 2009]. All but one configurations lead unequivocally to one and only one end state: on one side, this means that none of those system configurations is a minimal cut set of the system; on the other side, it also means that even when the order of the events in the sequence is accounted for this is not sufficient to unequivocally determine the consequent system end state, which depends also on the timing and magnitude of the occurring failures. The difficulties of the traditional approach to safety and reliability analysis appear clearly. 


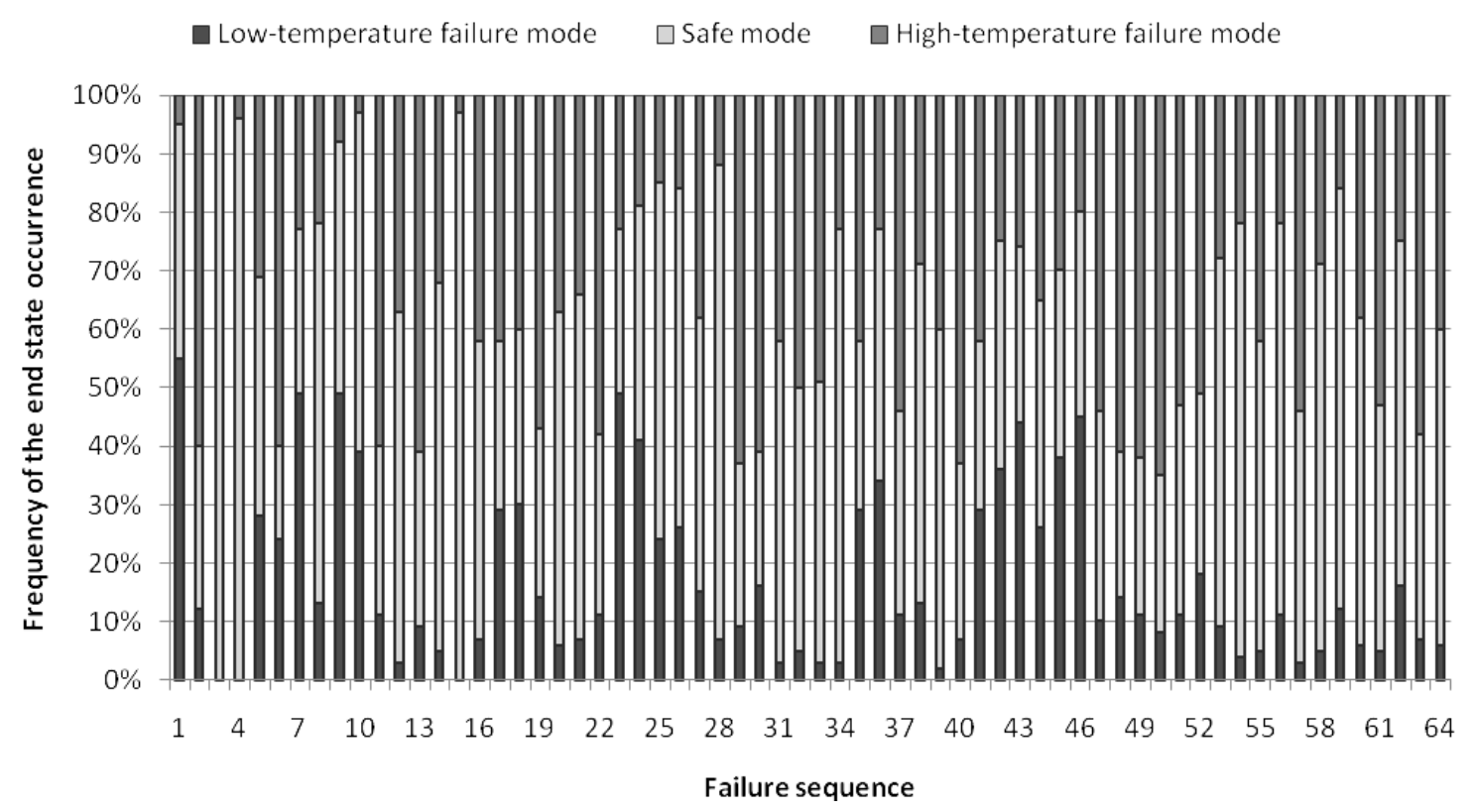

Figure 9 Stacked bar chart of the frequency of end states for each of the 64 accident scenarios listed in Table 1

\section{Processing dynamic scenarios for classification}

The processing of the dynamic scenarios here performed aims at identifying classes of behavioural similarity in the scenario evolutions in terms of the characteristic features of the accident sequences and at relating them with the three possible end states of the system, which define the classes. The characteristics of these classes constitute information that could allow identifying the prime implicants of the system.

The classification approach adopted is founded on a FCM clustering algorithm fed by FPCs of a selected safety variable (Appendix A at the end of the paper) [Ramsay et al., 2005] and optimized by mean of a supervised evolutionary search scheme (Appendix B at the end of the paper) [Bezdek, 1981; Zio et al., 2005; Mercurio et al., 2008].

\subsection{The supervised evolutionary clustering classifier based on functional principal components}

In mathematical terms, the target of the supervised optimization is to find optimal Mahalanobis metrics which define $c$ geometric clusters of the available data set which minimize the distance $D\left(\Gamma^{t}, \Gamma\right)$ between the a priori known physical class partition $\Gamma^{t} \equiv\left(\Gamma_{1}^{t}, \Gamma_{2}^{t}, \ldots, \Gamma_{c}^{t}\right)$ and the obtained geometric cluster partition $\Gamma \equiv\left(\Gamma_{1}, \Gamma_{2}, \ldots, \Gamma_{c}\right)$ (in this case $c$ corresponds to the possible end states):

$$
D\left(\Gamma^{t}, \Gamma\right)=\sum_{i=1}^{c} \frac{D\left(\Gamma_{i}^{t}, \Gamma_{i}\right)}{c}=\sum_{i=1}^{c} \sum_{k=1}^{N} \frac{\left|\mu_{i}^{t}\left(\vec{x}_{k}\right)-\mu_{i}^{*}\left(\vec{x}_{k}\right)\right|}{N \cdot c}
$$

where $0 \leq \mu_{i}^{t}\left(\vec{x}_{k}\right) \leq 1$ is the a priori known membership of the $k$-th pattern $\vec{x}_{k}$ to the $i$-th physical class (possibly not known with absolute precision, in which case it has a membership less than one) and $0 \leq \mu_{i}^{*}\left(\vec{x}_{k}\right) \leq 1$ is the membership to the corresponding geometric cluster in the feature space. 
The overall iterative training scheme for the supervised optimization leading to the identification of the optimal Mahalanobis metrics and the corresponding clusters is given in Appendix B at the end of the paper.

Note that the use of individual specific Mahalanobis metrics for defining the different clusters allows obtaining different ellipsoidal shapes and orientations of the clusters that can more adequately fit the actual data partition than the traditional Euclidean metric which leads to spherical clusters [Yuan et al., 1997].

When fed with a new pattern of feature values $\vec{x}$ of a given dynamic scenario, the trained classification algorithm provides the values of the membership functions $\mu_{i}^{*}(\vec{x}), i=1,2, \ldots, c$, to the different clusters which represent the scenario classes in the stochastic and process variable feature space.

Within the analysis presented in this work, $\vec{x}_{k}$ consists of the FPCs of the selected safety parameter (i.e., the average temperature of the LBE coolant $T_{L B}^{a v, C}$ ) in the time interval $[0,3000]$ [s] (for more details on FPCs, see Appendix A at the end of the paper).

\section{LBE-XADS fault scenario classification by FCM}

The three classes $(c=3)$ which supervise the construction of the clusters in the feature space correspond to the three system end states which may arise in the dynamic scenarios generated by the accident sequences:

class 1: low-temperature failure mode, with the safety parameter (i.e., the diathermic oil temperature $T_{o}^{a v, S}$ ) falling below the lower threshold $T_{o}^{t h, l}$

class 2: safe transients, with the safety parameter $T_{o}^{a v, S}$ remaining within the allowed range $\left[T_{o}^{t h, l}, T_{o}^{t h, u}\right]$

class 3: high-temperature failure mode, with the safety parameter $T_{o}^{a v, S}$ rising beyond the upper threshold $T_{o}^{t h, u}$

From the training sample, the main uncorrelated modes of variability in time (i.e., the FPCs) of the average temperature of the LBE coolant $T_{L B}^{a v, C}$ (the safety parameter) are identified (see the Appendix B) [Ramsay et al., 2005]. In Figure 10, the $T_{L B}^{a v, C}$ patterns are shown together with their representation by means of the first $\left(T_{L B, P C_{1}}^{a v, C}\right)$, first and second $\left(T_{L B, P C_{1}}^{a v, C}, T_{L B, P C_{2}}^{a v, C}\right)$, first, second and third functional principal components $\left(T_{L B, P C_{1}}^{a v, C}, T_{L B, P C_{2}}^{a v, C}\right.$ and $\left.T_{L B, P C_{3}}^{a v, C}\right)$. The FPCs are able to efficiently capture the characteristics of the original $T_{L B}^{a v, C}$ patterns and thus of the underlying stochastic sequence of failures; on the other hand, they may lack a complete interpretation in reliability terms. In this case, the first principal component $T_{L B, P C_{1}}^{a v, C}$ (explaining by itself $93.5 \%$ of the total variability) is clearly identifiable as a factor indicating to what extent $T_{L B}^{a v, C}$ is increasing in time (Figure 11); on the contrary, the interpretation of the second and third principal components are less clear. 

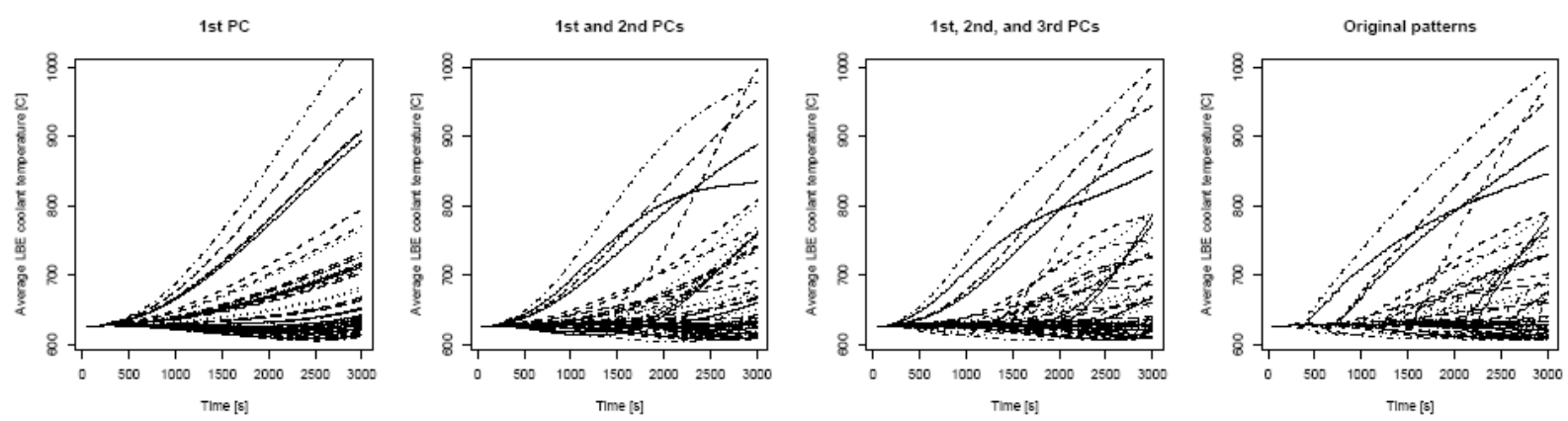

Figure $10 \mathrm{~A}$ sub-sample of sixty-four $T_{L B}^{a v, C}$ patterns as cumulatively described by means of the first, first and second, first, second and third functional principal components together with the original $T_{L B}^{a v, C}$ patterns
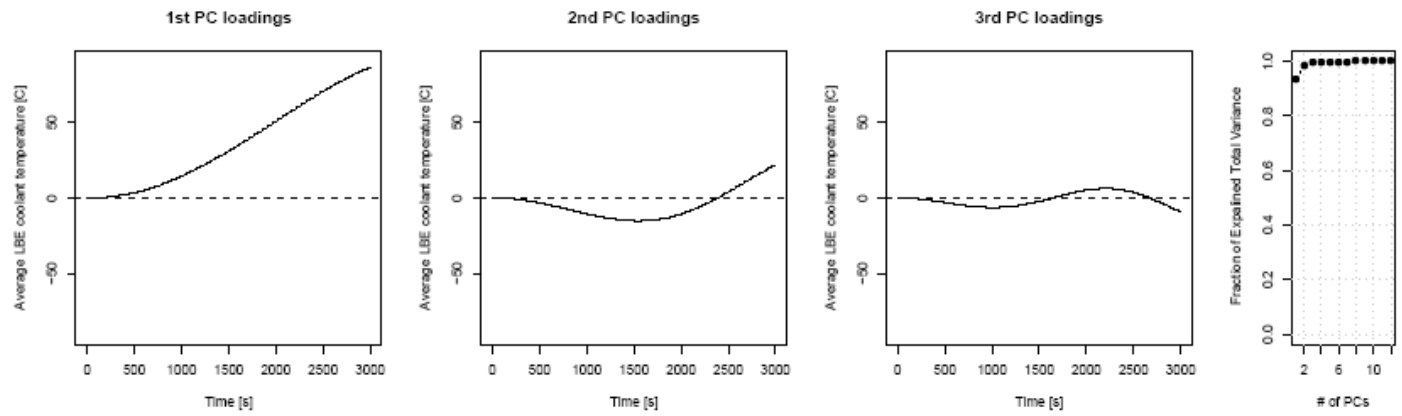

Figure 11 First, second, and third functional principal components. On the far right, cumulative fraction of the explained total variance

The training of the FCM classifier (and of the KNN and CART classifiers used for comparison) has been performed on the basis of a set of $N=6400$ class-labeled patterns (generated by 100 sampled realizations for each of the 64 accident sequences of Table 1) each one represented by means of one input vector and one output (the system end state class label 1,2 or 3); the sampled training patterns turn out to be distributed as follows among the $c=3$ classes of system end states: $N_{1}=1527$ belong to class $1, N_{2}=2399$ to class 2 and $N_{3}=2474$ to class 3 .

Three possible input vectors have been considered to test the classifier performances:

$$
\begin{array}{ll}
\left(T_{L B, P C_{1}}^{a v, C}\right): & \text { first principal component of } T_{L B}^{a v, C} \\
\left(T_{L B, P C_{1}}^{a v, C}, T_{L B, P C_{2}}^{a v}\right): & \text { first and second principal components of } T_{L B}^{a v, C} \\
\left(T_{L B, P C_{1}}^{a v, C}, T_{L B, P C_{2}}^{a v, C}, T_{L B, P C_{3}}^{a v, C}\right): & \text { first, second, and third principal components of } T_{L B}^{a v, C}
\end{array}
$$

Once constructed, the classifier can be used to classify any pattern of dynamic scenarios. In the present work, a total of $M=1280$ newly simulated accident scenarios of the three classes have been fed for classification by the fuzzy clustering classifier. These new scenarios are generated from the 64 possible accident sequences of Table 1 by sampling new realizations of the times of occurrence and magnitudes of the failure events (20 for each ordered sequence).

The error rate of classification of the test patterns provided by the FCM classifier is summarized in Table 2: patterns are assigned to the class for which the membership value of the pattern is the highest. For comparison, the error rate when $\bar{T}_{L B}^{a v, C}$ (the mean value over the transient duration of 3000 [s] of the average temperature of the LBE coolant $T_{L B}^{a v, C}$ ) is considered as the most important feature for the post-processing clustering analysis is also reported as in [Zio et al., 2009]. 


\begin{tabular}{|l|c|}
\hline Misclassification error rate & $F C M$ \\
\hline$\left(\bar{T}_{L B}^{a v, C}\right)$ & $16.65 \%$ \\
\hline$\left(T_{L B, P C_{1}}^{a v, C}\right)$ & $11.64 \%$ \\
\hline$\left(T_{L B, P C_{2}}^{a v, C}, T_{L B, P C_{2}}^{a v, C}\right)$ & $9.06 \%$ \\
\hline$\left(T_{L B, P C_{1}}^{a v, C}, T_{L B, P C_{2}}^{a v, C}, T_{L B, P C_{3}}^{a v, C}\right)$ & $5.25 \%$ \\
\hline
\end{tabular}

Table 2 Results of the classifier for different sets of FCP of the process variable $T_{L B}^{a v, C}$ and its mean value $\bar{T}_{L B}^{a v, C}$

The analysis of the misclassification performance highlights the improved performance of the FCM based on FPC with respect to the methodology originally developed and presented in [Zio et al., 2009]. The reason stands in the capability of FPCs in capturing relevant features of the stochastic sequences of failures, which are otherwise partially hidden when considering the safety relevant parameter $\bar{T}_{L B}^{a v, C}$ and almost completely missing when analyzing it by resorting to static approaches (Figure 6).

\section{Comparisons with KNN and CART classifiers}

In this Section, the misclassification error rates of the test patterns associated to the FCM classifier are compared with those of the KNN and CART classifiers [Hastie et al., 2001; Breiman et al., 1984]. The KNN classifier is a non-parametric classification method; the central idea of this method is to determine the unknown class of a new pattern looking at the known classes of its neighbors. More specifically, the classification of a new pattern is done by assignment to the class whose frequency is the highest among the $k$ th nearest neighbors of the new pattern, where the $k$ th nearest neighbors are the $k$ patterns of the training sample that are closest to the new pattern according to the Euclidean distance [Hastie et al., 2001]. A CART classifier is essentially a recursive dicotomic partition of the input space in which each element of the partition (namely, the leaves of the tree) is associated to a class; classification of a new pattern is done by assignment to the class whose frequency is the highest among the patterns of the training sample within the leaf of the tree which the new pattern belongs to; maximization of the decrement of the Gini index is used as growing criterion [Breiman et al., 1984], and minimization of the 10-fold crossvalidation misclassification error is used as pruning criterium [Breiman et al., 1984]. In Table 3, the misclassification error rate on $\mathrm{M}=1280$ newly simulated patterns are reported (columns refer to the different classifiers, rows refer to the different input vectors).

\begin{tabular}{|l|c|c|c|}
\hline Misclassification error rate & $F C M$ & $K N N$ & $C A R T$ \\
\hline$\left(\bar{T}_{L B}^{a v, C}\right)$ & $16.65 \%$ & $13.59 \%$ & $13.75 \%$ \\
\hline$\left(T_{L B, P C_{1}}^{a v, C}\right)$ & $11.64 \%$ & $11.25 \%$ & $11.48 \%$ \\
\hline$\left(T_{L B, P C_{1}}^{a v}, T_{L B, P C_{2}}^{a v, C}\right)$ & $9.06 \%$ & $5.86 \%$ & $8.98 \%$ \\
\hline$\left(T_{L B, P C_{1}}^{a v,}, T_{L B, P C_{2}}^{a v, C}, T_{L B, P C_{3}}^{a v, C}\right)$ & $5.25 \%$ & $4.45 \%$ & $8.67 \%$ \\
\hline
\end{tabular}

Table 3 Results of the classifiers for different sets of FCP of the process variable $T_{L B}^{a v, C}$ and its mean value $\bar{T}_{L B}^{a v, C}$ 
As expected, because of the massive size of the training sample, the KNN classifier (that is fully non-parametric) performs similarly or better than both FCM and CART classifiers for all possible input vectors; this might not be confirmed for smaller training samples.

Functional principal components appear to be effective not only in terms of descriptiveness (more of the $99 \%$ of the total variability is explained by the first three principal components, as shown in Figure 11), as expected, but also in terms of discriminating power. For instance, focusing on the FCM classifier, using the first three principal components of the average temperature of the LBE coolant $\left(T_{L B, P C_{1}}^{a v, C}, T_{L B, P C_{2}}^{a v, C}\right.$ and $\left.T_{L B, P C_{3}}^{a v, C}\right)$ the classifier is able to correctly classify nearly 19 patterns out of $20(94.75 \%)$, while using the mean value of the average temperature of the LBE coolant $\bar{T}_{L B}^{a v, C}$ it is able to correctly classify nearly 17 patterns out of $20(83.35 \%)$.

\section{Conclusions}

Dynamic approaches to system safety and reliability analysis embed the physical models of process dynamics into the stochastic models governing the hardware, software, human components failure behavior. To capture the different system behaviors which arise, a large number of time-dependent scenarios of possible system evolutions are simulated and then interpreted for drawing conclusions on the system safety and reliability characteristics.

This paper has addressed the problem of processing the numerous scenarios arising from a dynamic system safety and reliability analysis. With reference to a literature case study regarding the LBEXADS system, a Fuzzy C-Means clustering approach has been presented for classifying scenarios with similar characteristics described by the Functional Principal Components (FPCs) of a selected safety parameter whose behavior is affected by the occurred events. The classification approach is based on the use of FPCs within an optimized fuzzy clustering scheme. The system end states of interest and the relative safety parameter are identified a priori by expert judgment on the basis of the analysis of the system design, logic and dynamics of the LBE-XADS system. In the case study presented, the safety parameter is the diathermic oil secondary coolant temperature which cannot exceed lower and upper thresholds otherwise the system enters low- and high-temperature failure modes, respectively.

The application of the approach to the case study considered has demonstrated:

- the feasibility of the proposed approach of dynamic accident scenarios post-processing for retrieving safety-relevant information, and

- the increased classification performance when relying on FPCs of the selected safety relevant parameters, with respect to other characteristic features.

A comparison with the KNN and CART classification approaches has confirmed these findings.

Future research could investigate to what extent the results are robust to changes in the Monte Carlo (MC) sampling procedure, and further develop the methodology aiming at the identification of the prime implicants of the system under analysis (dynamic analogue of minimal cut sets) to be included into PRA. 


\section{References}

[Acosta et al., 1993] Acosta, C. and Siu, N., Dynamic Event Trees in Accident Sequence Analysis: Application to Steam Generator Tube Rupture, Reliab.Engng \& System Safety, 41, 135-154, 1993.

[Aldemir et al., 2008] Aldemir, T., Guarro, S., Kirschenbaum, J., Mandelli, D., Mangan, L. A., Bucci, P., Yau, M., Johnson, B., Elks, C., Ekici, E., Stovsky, M. P., Miller, D. W., Sun, X., Arndt, S. A., A Benchmark Implementation of Two Dynamic Methodologies for the Reliability Modeling of Digital Instrumentation and Control Systems, NUREG-CR Report Draft, 2008.

[Amendola et al., 1984] Amendola, A. and Reina, G., DYLAM-1, A Software Package for Event Sequence and Consequence Spectrum Methodology, EUR-924, CEC-JRC, ISPRA, Commission of the European Communities, 1984.

[Ansaldo, 2001] Ansaldo, 2001. XADS PbBi Cooled Experimental Accelerator Driven System Reference Configuration, Ansaldo Nuclear Division Summary Report ANSALDO ADS 1 SIFX 0500.

[Bezdek, 1981] Bezdek, J.C., Pattern Recognition With Fuzzy Objective Function Algorithms, Plenum, New York, 1981.

[Bowman et al., 1992] Bowman, C.D., Arthur, E.D., Lisowski, P.W., Lawrence, G.P., Jensen, R.J., Anderson, J.L., Blind, B., Cappiello, M., Davidson, J.W., England, T.R., Engel, L.N., Haight, R.C., Hughes, H.G., Ireland, J.R., Krakowski, R.A., LaBauve, R.J., Letellier, B.C., Perry, R.T., Russell, G.J., Staudhammer, K.P., Versamis, G., Wilson, W.B., 1992. Nuclear energy generation and waste transmutation using an accelerator-driven intense thermal neutron source. Nucl. Instr. Meth. Phys. Res. A 320, 336.

[Breiman et al., 1984] Breiman, L., Friedman, J. H., Olshen, R. A., Stone, C. J., Classification and regression trees. Wadsworth Statistics/Probability Series. Wadsworth Advanced Books and Software, Belmont, CA, 1984.

[Cammi et al., 2006] Cammi, A., Luzzi, L., Porta, A. A. and Ricotti, M. E., Modelling and control strategy of the Italian LBE-XADS, Progress in Nuclear Energy, Volume 48, Issue 6, August 2006, Pages 578-589.

[Carminati et al., 1993] Carminati, F., Klapisch, R., Revol, J.P., Roche, Ch., Rubio, J.A., Rubbia, C., 1993. An Energy Amplifier for Cleaner and Inexhaustible Nuclear Energy Production Driven by a Particle Beam Accelerator. CERN Report CERN-AT-93-47(ET).

[Cojazzi, 1996] Cojazzi, G., The DYLAM Approach to the Dynamic Reliability Analysis of Systems, Reliab.Engng \& System Safety, 52, 279-296, 1996.

[Devooght et al., 1992a] Devooght, J. and Smidts, C., Probabilistic Reactor Dynamics - I: The Theory of Continuous Event Trees, Nuclear Science and Engineering, Vol. 111, pp. 229-240, 1992.

[Devooght et al., 1992b]Devooght, J. and Smidts, C., Probabilistic Reactor Dynamics - II: A Monte-Carlo Study of a Fast Reactor Transcient, Nuclear Science and Engineering, Vol. 111, pp. 241-256, 1992.

[Devooght, 1997] Devooght, J., Dynamic reliability, Advances in Nuclear Science and Technology 25, pp. 215-278, 1997.

[Dufour et al, 2002] Dufour, F. and Dutuit, Y., Dynamic Reliability: A New Model, 13 ${ }^{\text {th }}$ ESREL2002 European Conference, Lyon-France, 18-21 March 2002.

[Garret et al., 2002] Garret, C. J. and Apostolakis, G. E., Automated Hazard Analysis of Digital Control Systems, Reliab.Engng \& System Safety, 77, 1-17, 2002.

[Guarro et al., 1996] Guarro, S., Yau, M. and Motamed, M., Development of Tools for Safety Analysis of Control Software in Advanced Reactors, NUREG/CR-6465, U.S. Nuclear Regulatory Commission, Washington, D.C., 1996. 
[Jain et al, 1988] Jain, A., Dubes, R., Algorithms for Clustering Data, Prentice Hall, Englewood Cliffs, NJ, 1988.

[Halmos, 1944] Halmos P. R.. Random Alms, The Annals of Mathematical Statistics, Vol. 15, No. 2, pp. 182-189, 1944.

[Hastie et al., 2001] Hastie, T., Tibshirani, R., Friedman, J., The elements of statistical learning. Data mining, inference, and prediction. Springer Series in Statistics. Springer-Verlag, New York, 2001.

[Klir et al., 1995] Klir, G., Yuan, B., Fuzzy Sets and Fuzzy Logic: Theory and Application, Prentice Hall, Englewood Cliffs, NJ, 1995.

[Labeau, 1996] Labeau P.E., Probabilistic Dynamics: estimation of generalized unreliability thought efficient Monte Carlo simulation, Annals of Nuclear Energy 1996, 17; 1355-1369.

[Labeau et al., 2000] Labeau, P.E., Smidts, C., Swaminthan, S., Dynamic Reliability: Towards an Integrated Platform for Probabilistic Risk Assessment. Reliability Engineering and System Safety 68, pp. 219-254, 2000.

[Marchand et al., 1998] Marchand, S., Tombuyes, B. and Labeau, P., DDET and Monte Carlo Simulation to Solve Some Dynamic Reliability Problems, PSAM 4, 3, 2055-2060, New York, 1998.

[Medjoudj et al., 2004] Medjoudj, M., Khalfaoui, S., Demmou, H., Valette, R., A Method for Deriving Feared Scenarios in Hybrid Systems, Probabilistic Safety Assessment and Management (PSAM7-ESREL04), Berlin-Germany, 14-18 June 2004.

[Mercurio et al., 2008] Mercurio, D., Podofillini, L., Zio, E., Dang, V.N., Identification and classification of dynamic event tree scenarios via possibilistic clustering: application to a steam generator tube rupture event, Journal Accident Analysis and Prevention, doi:10.1016/j.aap.2008.08.013, 2008.

[Peterson, 1977] Peterson, J. L., Petri Nets, ACM Computing Surveys, 9, 223-252, 1977.

[Ramsay et al., 2005] Ramsay, J.O., Silverman, B.W., Functional Data Analysis. Second Edition, New York Springer, 2005.

[Rubbia et al., 1995] Rubbia, C., Rubio, J.A., Buono, S., Carminati, F., Fitier, N., Galvez, J., Gels, C., Kadi, Y., Klapisch, R., Mandrillon, P., Revol, J.P., Roche, Ch., 1995. Conceptual Design of a Fast Neutron Operated High Power Energy Amplifier. CERN Report CERN-AT-95-44(ET).

[Rutt et al., 2006] Rutt, B., Catalyurek, U., Hakobyan, A., Metzroth, K., Aldemir, T., Denning, R., Dunagan, S. and Kunsman, D., Distributed Dynamic Event Tree Generation for Reliability and Risk Assessment, 1-4244-0420-7/06, IEEE, 2006.

[Siu, 1994] Siu, N., Risk assessment for dynamic systems: an overview, Reliability Engineering and System Safety, 43, 43-73, 1994.

[Smidts, 1994] Smidts, C., Probabilistic Dynamics: a comparison between continuous event trees and a discrete event tree model, Reliability Engineering and System Safety, 44(2), 189-206, 1994.

[Swaminathan et al., 1999] Swaminathan, S. and Smidts, C., The Event Sequence Diagram Framework for Dynamic PRA, Reliability Engineering and System Safety 63, pp. 73-90, 1999.

[Van Tuyle et al., 1993] Van Tuyle, G.J., Todosow, M., Geiger, M.J., Aronson, A.L., Takahashi, H., Accelerator-driven subcritical target concept for transmutation of nuclear wastes. Nucl. Technol. 101, 1, 1993.

[Venneri et al., 1993] Venneri, F., Bowman, C.D., Jameson R., 1993. Accelerator-driven Transmutation of Waste (ATW) - A New Method for Reducing the Long-term Radioactivity of Commercial Nuclear Waste. Los Alamos Report LA-UR-93-752.

[Yuan et al., 1997] Yuan B., and Klir G., Data driven identification of key variables, In: Ruan, D. (Ed.), Intelligent Hybrid Systems Fuzzy Logic, Neural Network, and Genetic Algorithms. Kluver Academic Publishers, Ch. 7, pp. 161-187, 1997. 
[Zio et al., 2005] Zio E. and Baraldi P., Identification of Nuclear Transients via Optimized Fuzzy Clustering, Annals of Nuclear Energy, Vol. 32, pp 1068-1080, 2005.

[Zio et al., 2009] Zio E. and Di Maio, F., Processing Dynamic Scenarios from a Reliability Analysis of a Nuclear Power Plant Digital Instrumentation and Control System, Annals of Nuclear Energy, doi:10.1016/j.anucene.2009.06.012, 2009. 


\section{APPENDIX A}

The basic concepts pertaining to Functional Principal Component Analysis (FPCA) as a tool for dimensional reduction are here presented.

Let $F$ be a random function such that

$$
E\left[\int_{a}^{b} F^{2}(t) d t\right]<+\infty
$$

with $\mu(t)=E[F(t)]$ being its mean function and $\sigma(t, s)=E[F(t) F(s)]$ its covariance function, and thus the kernel of its covariance operator. Often $\mu(t)$ and $\sigma(t, s)$ are not known and thus need to be estimated. Sample mean and sample covariance function provide consistent estimates of $\mu(t)$ and $\sigma(t, s)$; thus, if the sample size is sufficiently large, they can be used to estimate functional principal components.

It can be proven that under assumption (2), the set $\left\{\Phi_{1}, \Phi_{2}, \ldots\right\}$ of the eigenfunctions of the covariance operator forms an orthonormal basis for $L^{2}([a, b])$, i.e. the space which the realizations of the random function $F$ belong to.

Thus, $F$ can be decomposed as follows:

$$
F(t)=\mu(t)+\sum_{k=1}^{\infty} F_{k} \Phi_{k}(t) \text { with } F_{k}=\int_{a}^{b}(F(t)-\mu(t)) \Phi_{k}(t) d t
$$

The function $\Phi_{k}$ is known as the $k$ th functional principal component and $F_{k}$ as the score relative to the $k$ th functional principal component.

Moreover, it can be proven that $\operatorname{var}\left[F_{k}\right]=\lambda_{k}$ with $\lambda_{k}$ being the eigenvalue associated to the eigenvector $\Phi_{k}$ (i.e. $\left.\lambda_{k} \Phi_{k}(s)=\int_{a}^{b} \sigma(t, s) \Phi_{k}(t) d t\right)$ and $\operatorname{cor}\left[F_{k}, F_{k^{\prime}}\right]=\delta_{k k^{\prime}}$ (i.e. scores related to different functional principal components are uncorrelated scalar random variable). Note that $\Phi_{1}, \Phi_{2}, \Phi_{3}, \ldots$ are ordered such that $\lambda_{1} \geq \lambda_{2} \geq \ldots \geq 0$.

Let $F^{q}(t)=\mu(t)+\sum_{k=1}^{q} F_{k} \Phi_{k}(t)$ be the projection of $F$ on the $q$-dimensional affine space centered on the mean function generated by the first $q$ principal components.

It can be proven that the approximation obtained by means of this projection is "statistically optimal". Indeed, identifying with $S_{q} \subset L^{2}([a, b])$ a generic $q$-dimensional affine space centered on the mean function and with $\mathrm{P}_{S_{q}}$ the orthogonal projector on this space, it can be proven that:

$$
E\left[\int_{a}^{b}\left(F(t)-F^{q}(t)\right)^{2} d t\right]=\arg \min _{\mathrm{P}_{S_{q}}} E\left[\int_{a}^{b}\left(F(t)-\mathrm{P}_{S_{q}} F(t)\right)^{2} d t\right]
$$

Hence, the approximation obtained by representing $F$ through its first $q$ principal components minimizes the expected quadratic error over any other $q$-dimensional representation.

The effectiveness of this approximation can be easily quantified by means of the so called "fraction of explained total variance", i.e.: 


$$
\frac{E\left[\int_{a}^{b}\left(F^{q}(t)-\mu(t)\right)^{2} d t\right]}{E\left[\int_{a}^{b}(F(t)-\mu(t))^{2} d t\right]}=1-\frac{E\left[\int_{a}^{b}\left(F(t)-F^{q}(t)\right)^{2} d t\right]}{E\left[\int_{a}^{b}(F(t)-\mu(t))^{2} d t\right]}=\frac{\sum_{k=1}^{q} \lambda_{k}}{\sum_{k=1}^{\infty} \lambda_{k}}
$$

In the end, FPCA provides a useful tool to interpret and represent in a finite dimensional space with uncorrelated components, phenomena that are intrinsically non-finite and not immediately describable by means of uncorrelated components.

\section{APPENDIX B}

The iterative training scheme for the supervised optimization leading to the identification of the optimal Mahalanobis metrics and the corresponding cluster can be summarized as follows:

1. At the first iteration $(\tau=1)$, initialize the metrics of all the $c$ clusters to the Euclidean metrics, i.e. $\underline{\underline{M}}_{i}(1)=\underline{\underline{I}}, i=1,2, \ldots, c$, where $\underline{\underline{I}}$ is the identity matrix.

2. At the generic iteration step $\tau$, run the FCM clustering algorithm [Bezdek, 1981] to partition the $N$ training data into $c$ clusters of memberships $\Gamma(\tau)=\left\{\Gamma_{1}(\tau), \ldots, \Gamma_{c}(\tau)\right\}$, based on the current metrics $\underline{\underline{M}}_{i}^{+}(\tau)$ and on the "supervising" initial partition $\Gamma^{t}$ which sets the initial memberships of the $N$ patterns to $c$ clusters equal to the true memberships to the a priori known classes.

3. Compute the distance $D\left(\Gamma^{t}, \Gamma(\tau)\right)$ between the a priori known physical classes and the geometric possibilistic clusters. At the first iteration $(\tau=1)$ initialize the best distance $D^{+}$ to $D\left(\Gamma^{t}, \Gamma(\tau)\right), D_{i}^{+}$to $D\left(\Gamma_{i}^{t}, \Gamma_{i}(1)\right)$ and the best metrics $\underline{\underline{M}}_{i}^{+}$to $\underline{\underline{M_{i}}}(\tau)$ and go to step 5 .

4. If $\Gamma(\tau)$ is close to $\Gamma^{t}$, i.e. $D\left(\Gamma^{t}, \Gamma(\tau)\right)$ is smaller than a predefined threshold $\varepsilon$, or if the number of iterations $\tau$ is greater than the predefined maximum allowed number of iterations $\tau_{\max }$, stop: $\Gamma(\tau)$ is the optimal cluster partition $\Gamma^{*}$; otherwise, if $D\left(\Gamma^{t}, \Gamma(\tau)\right)$ is less than $D^{+}$upgrade $D^{+}$to $D\left(\Gamma^{t}, \Gamma(\tau)\right), \underline{\underline{M}}_{i}^{+}$to $\underline{\underline{M}}_{i}(\tau)$ and $D_{i}^{+}=D\left(\Gamma_{i}^{t}, \Gamma_{i}(1)\right)$.

5. Increment $\tau$ by 1 . Update each matrix $\underline{\underline{M}}_{i}^{+}$by exploiting its unique decomposition into Cholesky factors [Labeau, 1996], $\underline{\underline{M}}_{i}^{+}=\left\{\underline{\underline{G}}_{i}^{+}\right\}^{T} \underline{\underline{G}}_{i}^{+}$, where $\underline{\underline{G}}_{i}^{+}$is a lower triangular matrix with positive entries on the main diagonal. More precisely, at iteration $\tau$, the entries $g_{l_{1}, l_{2}}^{i}(\tau)$ of the Cholesky factor $\underline{\underline{G}}_{i}^{+}(\tau)$ are updated as follows:

$$
\begin{gathered}
g_{l_{1}, l_{2}}^{i}(\tau)=g_{l_{1}, l_{2}}^{i+}+N_{l_{1}, l_{2}}^{i}\left(0, \delta_{i}^{+}\right) \text {if } l_{1}<l_{2} \\
g_{l_{1}, l_{2}}^{i}(\tau)=\max \left(10^{-5}, g_{l_{1}, l_{2}}^{i+}+N_{l_{1}, l_{2}}^{i}\left(0, \delta_{i}^{+}\right)\right) \text {if } l_{1}=l_{2}
\end{gathered}
$$

where $\delta_{i}^{+}=\alpha D_{i}^{+}, \alpha$ is a parameter that controls the size of the random step of modification of the Cholesky factor entries $g_{l_{1}, l_{2}}^{i+}, N_{l_{1}, l_{2}}^{i}$ denotes a Gaussian noise with mean 0 and standard deviation $\delta$, and Eq. (7) ensures that all entries in the main diagonal of the matrices $\underline{\underline{G}}_{i}(\tau)$ are positive numbers and so $\underline{\underline{M}}_{i}(\tau)$ are definite positive distance 
matrices. Notice that the elements of the $i$-th Mahalanobis matrix are updated proportionally to the distance $D_{i}^{+}$between the $i$-th a priori known class and the $i$-th cluster found. In this way, only the matrices of those clusters which are not satisfactory for the classification purpose are modified.

6. Return to step 2. 